\title{
Art and cultural heritage - where analytical sciences contribute to preserve our heritage
}

\author{
Michel Sablier $^{1}$ (D) - Rémy Chapoulie ${ }^{2}$
}

Received: 10 November 2016 / Accepted: 15 November 2016/Published online: 9 January 2017

(C) Springer-Verlag Berlin Heidelberg 2016

EuroAnalysis 2015, the XVIII ${ }^{\text {th }}$ Scientific Meeting of the Euroanalysis series, was held at the Congress Center, Bordeaux, France, from September 6 to 10, 2015. A session devoted to the topic of cultural heritage studies was organized at the occasion of this international meeting.

The intense and fruitful exchanges between the conference attendees engaged during the tenue of the session "art and cultural heritage" clearly showed the concern in common that analytical scientists address to the problem of our cultural heritage preservation. If each case addressed by the question of artwork preservation can be specific to a material engaged in the observed degradation processes, the variety of expertise and techniques proposed to preserve artworks demonstrated that the scientific community feels in charge of bringing solutions for our cultural heritage protection.

For this special issue of ESPR, entitled "Art and cultural heritage - where analytical sciences contribute to preserve our heritage", contributions were solicited from those participants, who had made an oral or poster presentation at the Euroanalysis 2015. This compilation of application studies is addressed to the broader scientific community interested in cultural heritage issues. We formulate the wish that the

Responsible editor: Philippe Garrigues

Michel Sablier

michel.sablier@mnhn.fr

1 Sorbonne Universités, Centre de recherche sur la conservation (USR 3224), Muséum National d'Histoire Naturelle, Ministère de la Culture et de la Communication, CNRS, 36, rue Geoffroy Saint-Hilaire, CP 21-75005 Paris, France

2 IRAMAT-CRP2A, UMR CNRS 5060, Maison de l'Archéologie, Université Bordeaux Montaigne, Domaine Universitaire, Esplanade des Antilles, 33607 Pessac Cedex, France publication of this issue will give raise to an increased interest among the heritage scientist community for application of their works to ESPR.

In this special issue, two published articles refer directly to the fundamental question of corrosion processes to which metal artefacts are unavoidably faced. As a matter of fact, the presence of oxygen and water in the environment, the climatic conditions, the temperature, and the precipitation are responsible for the advent of moisture and oxidation processes initiating the formation of corrosion products with, in fine, deleterious effects in term of conservation.

In this aspect, controlling the corrosion of ferrous metal objects presents a real challenge to conservators as exposed by Watkinson and Emmerson in their evaluation on the impact of aqueous washing on the ability of akaganéite $(\beta-\mathrm{FeOOH})$ to corrode iron. Indeed, the versatility of use of iron alloys makes iron one of the most reactive and unstable species for heritage ironworks in many environments. Particularly, chloride reveals as a major accelerator for iron artefact corrosion when present and its presence may favour the occurrence of $\beta-\mathrm{FeOOH}$, known as an effective corrosion products for iron archaeological objects. Thus, it is of outmost interest to determine how the washing of $\beta$ - $\mathrm{FeOOH}$ can affect its ability to corrode iron under relatively high humidity conditions for the development of adapted methods in conservation practice when chloride and $\beta-\mathrm{FeOOH}$ interact in the corrosion process.

Similarly, the corrosion of outdoor bronze monuments is depending on the presence of oxygen and water to favour the formation of copper corrosion layers. The induced protection of these corrosion layers of different composition in correlation with the environmental conditions (e.g. through the formation of copper chlorides, copper sulphates) is controversial in their effectiveness. However, so far, conservation and restoration treatments used for copper-based alloys are mostly based on the application of protective organic coatings. 
These treatments act through a non-specific way without considering the differences in patina composition and corrosion product stability of the objects in simply creating a physical barrier for coating or in transforming active chemical species. Interestingly, Albini et al. proposed an eco-friendly and sustainable solution for the preservation of bronze artefacts through the use of biological treatment employing a specific copper-resistant fungal strain for stabilizing soluble and/or active copper corrosion products. This biopassivation treatment is based on the transformation of copper corrosion products into stable copper oxalates. The authors evaluated its application to tin-enriched bronze surfaces and sheltered or unsheltered exposed areas of outdoor monuments.

Application of analytical chemistry to cultural heritage materials, either for their identification or conservation purposes, relies on proven analytical methods. However, the benefit of their use in cultural heritage studies necessitates their improved application to answer questions relevant to the specificity of the materials. The other articles of this special issue give example of experiments conducted in the aim of characterizing materials: their origin, composition or provenance as well as their likely alterations.

Three articles refer to experiments carried out with gas chromatography and mass spectrometry. The first article reports qualitative and quantitative studies on the composition of sandarac resin by GC-MS (Kononenko et al.). By the past, sandarac resin was widely used as a protective varnish, as an additive and a fixative for artistic drawings. However, confusion exists in the exact definition of its properties, particularly in distinguishing between fresh resins and resins aged on purpose. The article tackles the question of sandarac molecular composition and characterization of markers that can be used for its identification. This work is challenging due to the fact that identified diterpenoids after liquid extraction were finally representing only 10 to $30 \%$ of the whole resin components: the difficulty of obtaining efficient extractions from sample to sample explains on one side the discrepancy in previously published results, and the other difficulty resides in the fact that non-extractable fraction of the sandarac resin constitutes the major part of the sample. However, the work of Konenko et al. permits to refine the identification of the diterpenoid components of sandarac, and their extended investigation on samples provided by several suppliers confirms qualitatively the discrepancy that one can expect from different sources of origin of the samples.

Analytical pyrolysis coupling with GC/MS is a widely used method in the domain of cultural heritage for its capacity to simply and quickly provide insights on polymer fingerprints as well as marker detection. Avataneo and Sablier propose the use of Py-GC/MS and GC/MS for the characterization of markers of origin in the aim of identifying the origin of traditional East Asian papers. Presently, the identification of ancient East Asian papers relies on microscopy for the identification of paper fibres, which is not straightforward, and may even reveal to be difficult due to the state of conservation of the museum samples. The development of a complementary technique based on infinitesimal sampling would be very useful for the analysis of archaeological papers. Py-GC/MS experiments conducted on traditional East Asian reference paper samples permitted to characterize a set of triterpenic and steroid compounds as markers of origin for those samples, and case study from an archaeological Chinese paper painting demonstrated its applicability to unknown samples. Applied for the first time to East Asian papers, the chosen Py-GC/MSbased approach opens the route for the definition of new criteria for characterization and identification of archaeological East Asian papers.

In conjunction to Py-GC/MS, a multi-analytical approach is proposed for the assessment of origin of geological amber samples belonging to the collection of the Earth Sciences Museum of the University of Bari Aldo Moro, Italy (van der Werf et al.). A sequence of non-invasive and microdestructive methods combining UV-fluorescence, ATR-FTIR spectroscopy and Py-GC/MS was applied for a complete chemical characterization and the correct identification of purported amber samples which revealed to be of copal origin for some of them or misclassified for the others. UV-fluorescence demonstrated its potential as a screening method for the identification of resinite or synthetic resins, while ATR-FTIR and Py-GC/MS revealed to be necessary for the complete chemical characterization of samples.

Finally, two other articles in the issue report analysis based on spectroscopy. Bassel et al. employed laser-induced breakdown spectroscopy (LIBS) for applications on calcitic alterations observed on the cave walls of ornate caves. The South West of France is a wealthy region of pre-historic caves where conservation concerns lays on the control of calcitic coatings onto the ornate walls. In the study, one cave classified as a laboratory cave with no archaeological evidence was investigated for each of the two common types of calcitic alterations showing two facies: moonmilk and coralloid. Two different LIBS systems were used and evaluated on the coralloid sample: a handheld system for on-site analysis and laboratory systems allowing multi-elemental image acquisition with high spatial resolution. This application of LIBS systems in both point and imaging modes reveals as promising for accurate on-site selection of the samples, while the imaging modes give more deep insights into the elemental composition and the likely migration characteristics of the selected elements of interest in the coralloid sample.

In the last article of this special issue, Ammari et al. apply chemometrics to cathodoluminescence imaging for the classification of pre-Columbian artefacts originated from Northern Peru. Ceramic cathodoluminescence imaging is conventionally used for description of samples: paste colour and inclusion. In the present study, the authors investigate a new approach based on RGB histogram analysis followed by an image processing 
generating dendrograms for the depiction of the samples and their final classification. Five types of ceramics are then differentiated completing efficiently the first archaeological classification based on morphological and aesthetical criteria.

Altogether, the articles presented in this special issue give a state of the art for the recent application of analytical methods to the investigation of artwork degradation processes and present new tools for our increased knowledge on artwork history, as well as their potential for their uses in real situation.

So, we are really grateful for researchers who attended the XVIII $^{\text {th }}$ Scientific Meeting of the Euroanalysis series and joined the session devoted to cultural heritage studies; we would like to congratulate the authors with present published papers. We are thankful for all participants who actively contributed to the success of the session, hoping that there will be other occasions to meet and exchange ideas and new scientific results in the domain of art and cultural heritage through applications of analytical sciences. Doctor Philippe Garrigues, editor-in-chief of Environmental Sciences and Pollution Research and co-chair of Euroanalysis 2015; Doctor Christian Rolando, co-chair of Euroanalysis 2015; and the editorial team of Environmental Sciences and Pollution Research are acknowledged for their endless help during the organization of the session art and cultural heritage and the review process of this special issue.

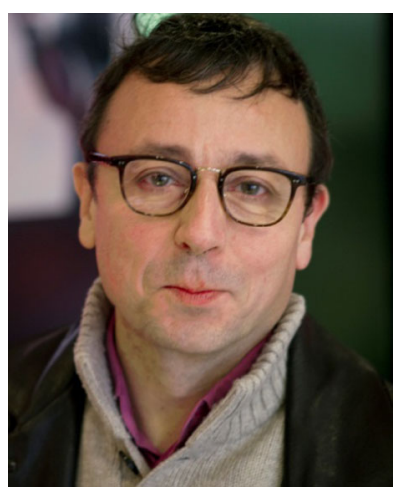

Michel Sablier has graduated in chemistry from the Université Pierre et Marie Curie, Paris, where he obtained his $\mathrm{PhD}$ in 1992. After a post-doctoral training in the Gorlaeus Laboratories, Leiden (the Netherlands), he joined the CNRS in 1994 and holds now a position of senior scientist. His scientific activity has been dedicated to mass spectrometry and its applications in several fields: instrumental development, gas-phase studies of ion-molecule and ion-radical reactions, and detection of emerging pollutants in the environment. In particular, the development of original methods for the characterization of radical species gave him the opportunity to develop collaborations in Japan where he stayed for 1 year in 2000-2001 with a fellowship from the Japan Society for the Promotion of Science (National Institute for Environmental Studies, Tsukuba). Beside fundamental chemistry studies, he has always motivated a deep interest for the applications of mass spectrometry to the domain of cultural heritage.

Three years ago, he joined the Centre de Recherche sur la Conservation at the Muséum National d'Histoire Naturelle, Paris. His research now addresses on topics related to cultural heritage. With a particular focus on cellulosic materials, his current research work concerns the characterization of markers of origin in traditional Asian papers and the understanding of deterioration mechanisms and contamination mechanisms in ancient papers. All of these studies use modern mass spectrometry methods. Michel Sablier joined ESPR as an editorial board member mid-2012.

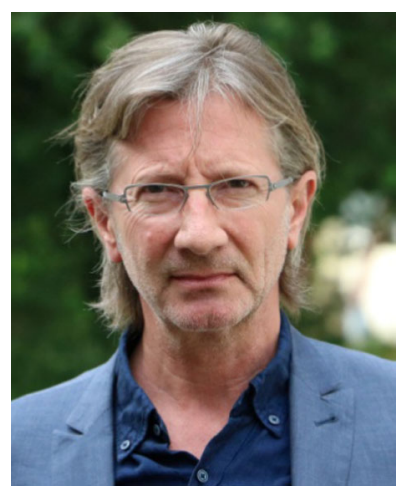

Rémy Chapoulie graduated in applied physics at the University of Bordeaux (sciences and technology). He took his $\mathrm{PhD}$ in 1988 at the University of Bordeaux Montaigne (human sciences) and his Habilitation at the University of Bordeaux in 2004 again in sciences and technology. Now he is University Professor of Physics in archaeometry. He was a member of the scientific commission at the CNRS in SHS (social and human sciences) from 2000 to 2004 and was a member of one of the commissions of research for the Aquitaine region from 2005 to 2010.

His main research activities currently concern the multiphysical study and archaeometry of ceramics and pigments from pre-Columbian Peru, the taphonomy of decorated pre-historical caves from Dordogne (France), the archaeometric study of antique marble from northern Spain, Portugal, and the South West of France, and the archaeological and archaeometrical investigation of Roman amphorae. He recently started some investigation on lithic materials (provenance, sourcing and distribution) in Corsica and the study of Japanese prints. One of his major and present interests lies in the development of mobile analytical systems for in situ measurements.

His scientific and administrative responsibilities are very closely linked to the sciences dedicated to the study of the cultural heritage. He is the head of the laboratory IRAMAT-CRP2A (Institut de recherche sur les archéomatériaux-Centre de recherche en physique appliquée à l'archéologie) UMR 5060 CNRS at Bordeaux and is a member of the scientific advisory board of the cluster of excellence called LabEx des Sciences Archéologiques de Bordeaux. This cluster gathers three research teams from Bordeaux with competences in archaeology, archaeometry, pre-history, physical anthropology and ancient history. Rémy Chapoulie joined ESPR as an editorial board member in close association with Michel Sablier in 2015. 